\title{
Geographical origin of an introduced insect pest, Listronotus bonariensis (Kuschel), determined by RAPD analysis
}

\author{
C. LENNEY WILLIAMS, S. L. GOLDSON*†, D. B. BAIRD $† \&$ D. W. BULLOCK \\ Centre for Molecular Biology, Animal and Veterinary Sciences Group, Lincoln University, P.O. Box 84, Canterbury, New \\ Zealand and $\dagger$ AgResearch, P.O. Box 60, Canterbury, New Zealand
}

\begin{abstract}
The Argentine stem weevil, Listronotus bonariensis (Kuschel) (Coleoptera: Curculionidae), is an important introduced pasture pest in New Zealand. In this study geographical populations of this species were analysed using polymerase chain reaction-based randomly amplified polymorphic DNA (RAPD), in an attempt to determine the geographical origin of the pest. Morphologically indistinguishable individuals were collected from nine South American, five New Zealand and one Australian populations. Ten primers were screened for usefulness, two of which revealed significant, scorable polymorphisms between these populations. The results indicated that the sampled New Zealand L. bonariensis populations originated from the east coast of South America.
\end{abstract}

Keywords: genetic variation, introduced species, Listronotus bonariensis, populations, RAPD.

\section{Introduction}

The Argentine stem weevil Listronotus bonariensis (Kuschel) (Coleoptera: Curculionidae) is an introduced pest (Goldson \& Emberson, 1980) attacking improved graminaceous pasture throughout New Zealand (Prestidge et al., 1991). The damage caused by this pest is estimated to range from \$NZ 78-251 million annually (Prestidge et al., 1991). Native to South America, L. bonariensis is thought to have been accidentally introduced to New Zealand and Australia; it was first reported in New Zealand in 1927 (Marshall, 1937) and, with the advent of pastoral grazing, quickly achieved pest status.

Elucidation of genetic variation in geographical populations can be an important aspect of pest studies (Kambhampati et al., 1990; Roehrdanz \& Johnson, 1988), providing insight into the geographical origin of colonized populations (Kambhampati et al., 1991). Within the native habitat, the extent of genetic variation between geographical populations depends on several factors, including gene flow between populations and time since separation (Hartl, 1980; Templeton et al., 1990). Genetic differences within the introduced population can be the result of the genetic variation in the founder population, the number of

*Correspondence. founding events and selection pressure (Baker \& Stebbins, 1965).

It is probable that $L$. bonariensis arrived in New Zealand (and Australia) less than 100 years ago, and given that 2-3 generations a year are possible (Kelsey, 1958) only about 200-250 generations can have elapsed since its establishment. Given that the New Zealand environment resembles that of South America, it is thought that selection pressures in the native and colonized habitats would be comparable. That, together with the short time since introduction, suggests genetic similarity between the introduced population and the population of origin might be high. However, founder effect, random genetic drift and/or recurrent introductions could have altered the colonized populations' genetic make-up.

In order to define the origin of pest populations it is necessary to demonstrate genetic similarities between colonized and potential source populations. This type of study can use numerous techniques including phenotypic variation, allozyme data, DNA data (restriction fragment length polymorphisms, sequence analysis), morphometrical analysis, or behavioural differences. With small insects, one common difficulty encountered with DNA analysis is lack of material. In this study, this problem was overcome using polymerase chain reaction-based randomly amplified polymorphic DNA (RAPDs) (Welsh \& McClelland, 1990; Williams, et al., 1990). 
This relatively new technique offers advantages with respect to the amount of material needed and the fact that nothing need be known about the genomic organization of the organism. The technique has generated useful results in the identification of unique individuals (Smith et al., 1992), detection of genetic variability (Chalmers et al., 1992; Landry et al., 1993), race identification (Crowhurst et al., 1991) and generation of linkage maps (Paran et al., 1991). The technique is becoming widely used (see Hedrick 1992 for a review of various current applications), and a review of potential applications has been given by Hadrys et al. (1992).

\section{Materials and methods}

\section{Sample collection}

Adult $L$. bonariensis were collected from nine climatically diverse localities in South America between September 1989 and February 1990 (Fig. 1). Methods of collection and transportation have been discussed elsewhere (Goldson et al., 1990). Samples were then frozen at $-100^{\circ} \mathrm{C}$ until use. Adult weevils were also collected from five localities in New Zealand in January and April 1992 (Fig. 2) and one locality in Australia (Flaxley, South Australia) in December 1991.

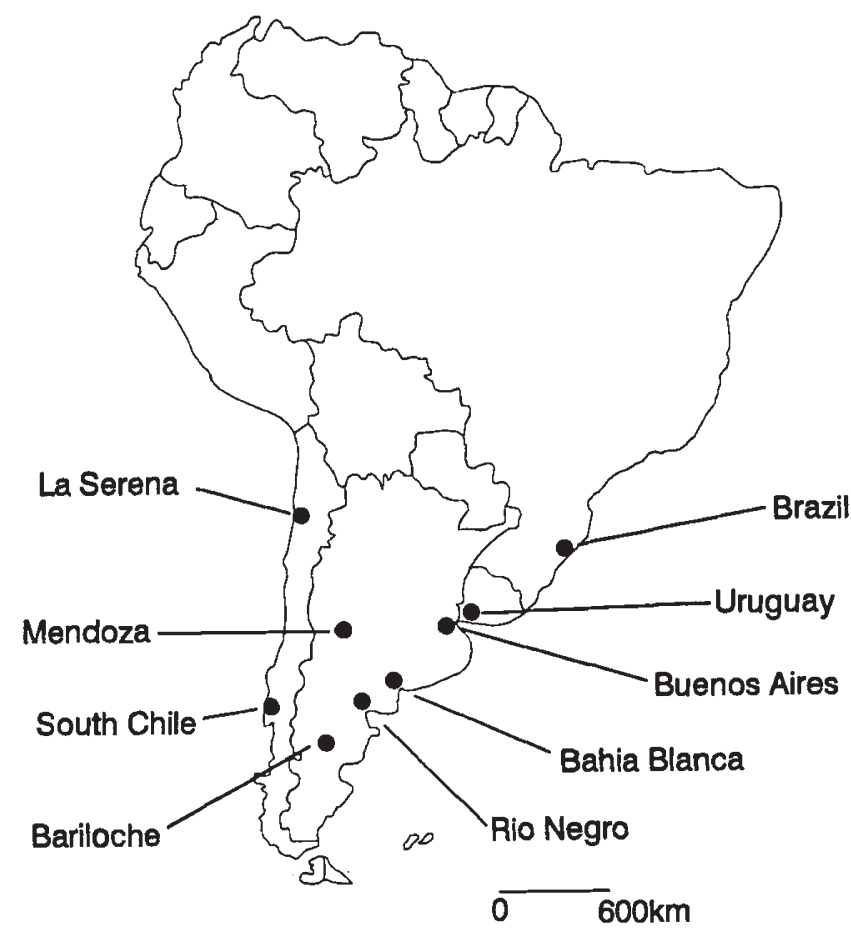

Fig. 1 South American Listronotus bonariensis collection sites.

\section{DNA isolation}

DNA was isolated from individual weevils. Each weevil was ground under liquid nitrogen and incubated in isolation buffer (8.5 mм Tris $p \mathrm{H} \mathrm{8,} 25 \mathrm{~mm}$ EDTA $p \mathrm{H} \mathrm{8,}$ 0.5 per cent SDS, $25 \mathrm{~mm} \beta$-mercaptoethanol and $0.5 \mathrm{mg} \mathrm{ml}^{-1}$ Proteinase $\mathrm{K}$ ) at $50^{\circ} \mathrm{C}$ for $1 \mathrm{~h}$ with occasional inverting. Following phenol:chloroform washes, the DNA was precipitated with 100 per cent ethanol and washed with 70 per cent ice-cold ethanol, then air dried and suspended in TE $(10 \mathrm{~mm}$ Tris $p \mathrm{H} 8.0,0.1$ mM EDTA) containing $25 \mu \mathrm{g} \mathrm{ml}^{-1}$ RNase A. The samples were incubated at $37^{\circ} \mathrm{C}$ for $30 \mathrm{~min}$, then diluted with $690 \mu \mathrm{l} \mathrm{H}_{2} \mathrm{O} .5 \mu \mathrm{l}$ of this DNA (approximately $30 \mathrm{ng}$ ) was used as a template for RAPD reactions. Each weevil yielded enough DNA for approximately $145 \mathrm{RAPD}$ reactions.

\section{Primer selection}

The primers used were 10-bp oligonucleotides of random sequence (Oligos Etc., Inc., Gullford, Connecticut). Ten primers were initially screened using pooled samples of DNA from each population, as follows. $20 \mu \mathrm{l}$ of DNA from each individual weevil within each population were pooled. $5 \mu \mathrm{l}$ (30 ng) were

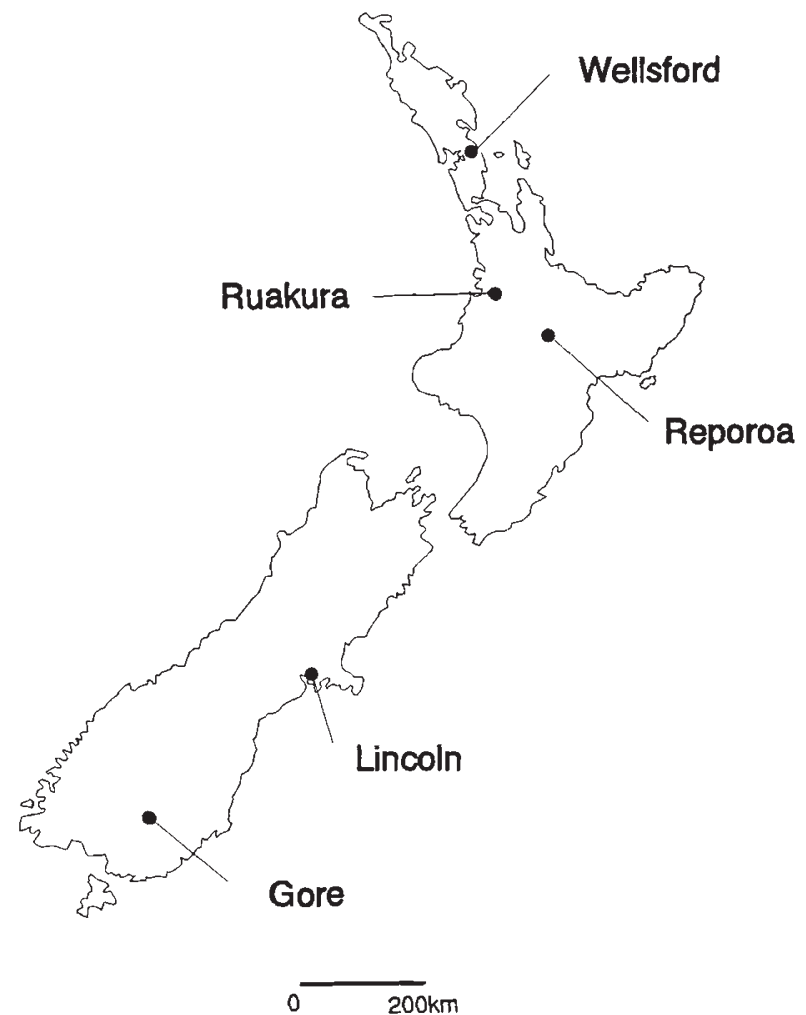

Fig. 2 New Zealand Listronotus bonariensis collection sites. 
then taken from each pooled sample as templates for the RAPD reaction. This resulted in one reaction for each population and made it possible to select useful primers. Primers were designated as useful if they generated few, distinct bands which showed polymorphisms between populations. Primers that generated many bands ( $>15$ per sample) were designated as unscorable and not pursued. Of the 10 primers initially screened, two were selected as potentially useful. These were primer 267/2 (5'-ACATAGACGG-3') and primer GT09 (5'-TCTGCCGTGA-3').

\section{RAPD reactions and electrophoresis}

RAPD reactions were carried out based on the methods developed by Williams et al. (1990) and Welsh and McClelland (1990). The 25- $\mu$ l reactions contained $0.4 \mathrm{~mm}$ dNTPs, $1 \mathrm{x}$ Taq polymerase buffer, 1 unit Taq polymerase, $30 \mathrm{ng}$ DNA and either primer 267/2 (200 nM) or primer GT09 (600 nM). Each reaction was overlaid with a drop of silicon oil.

The reaction profile was 45 cycles of $94^{\circ} \mathrm{C}$ for 1 $\min , 36^{\circ} \mathrm{C}$ for $1 \mathrm{~min}, 72^{\circ} \mathrm{C}$ for $2 \mathrm{~min}$. The samples were then held at $72^{\circ} \mathrm{C}$ for $5 \mathrm{~min}$. Amplifications were carried out on a Hybaid $\mathrm{PM}$ thermal reactor and were all carried out on the same thermocycler to eliminate the possibility of machine to machine variation. Ali- quots $(5 \mu \mathrm{l})$ of the amplification products were then electrophoresed at $65 \mathrm{~V}$ for $2 \mathrm{~h}$ through 1.4 per cent SeaKem ${ }^{\circ}$ LE Agarose in TBE ( $89 \mathrm{~mm}$ Tris, $89 \mathrm{~mm}$ boric acid, $2 \mathrm{~mm}$ EDTA) containing $0.25 \mu \mathrm{g} \mathrm{ml}^{-1}$ ethidium bromide and visualized using UV light.

Based on this protocol, the DNA from 12 individuals from each of the nine populations (except Brazil, in which case six individuals were used) was amplified by the two useful primers. This resulted in a banding pattern for each individual and also resulted in a population profile for each population. A negative control (without template DNA) was included in each set of reactions amplified. The same sample amplified with the same primer and under the same reaction conditions in different tubes on the same day or on different days resulted in the same bands (not shown). Amplification profiles were similar to those of DNA extracted from individual $L$. bonariensis wing muscles (not shown).

\section{Scoring of bands}

Only distinct bands were included in the data set. Each individual was scored for the presence (1) or absence $(0)$ of every such band. This was done by initially scoring against a molecular weight marker (BRL $1 \mathrm{~kb}$ ladder) and assigning tentative identification numbers
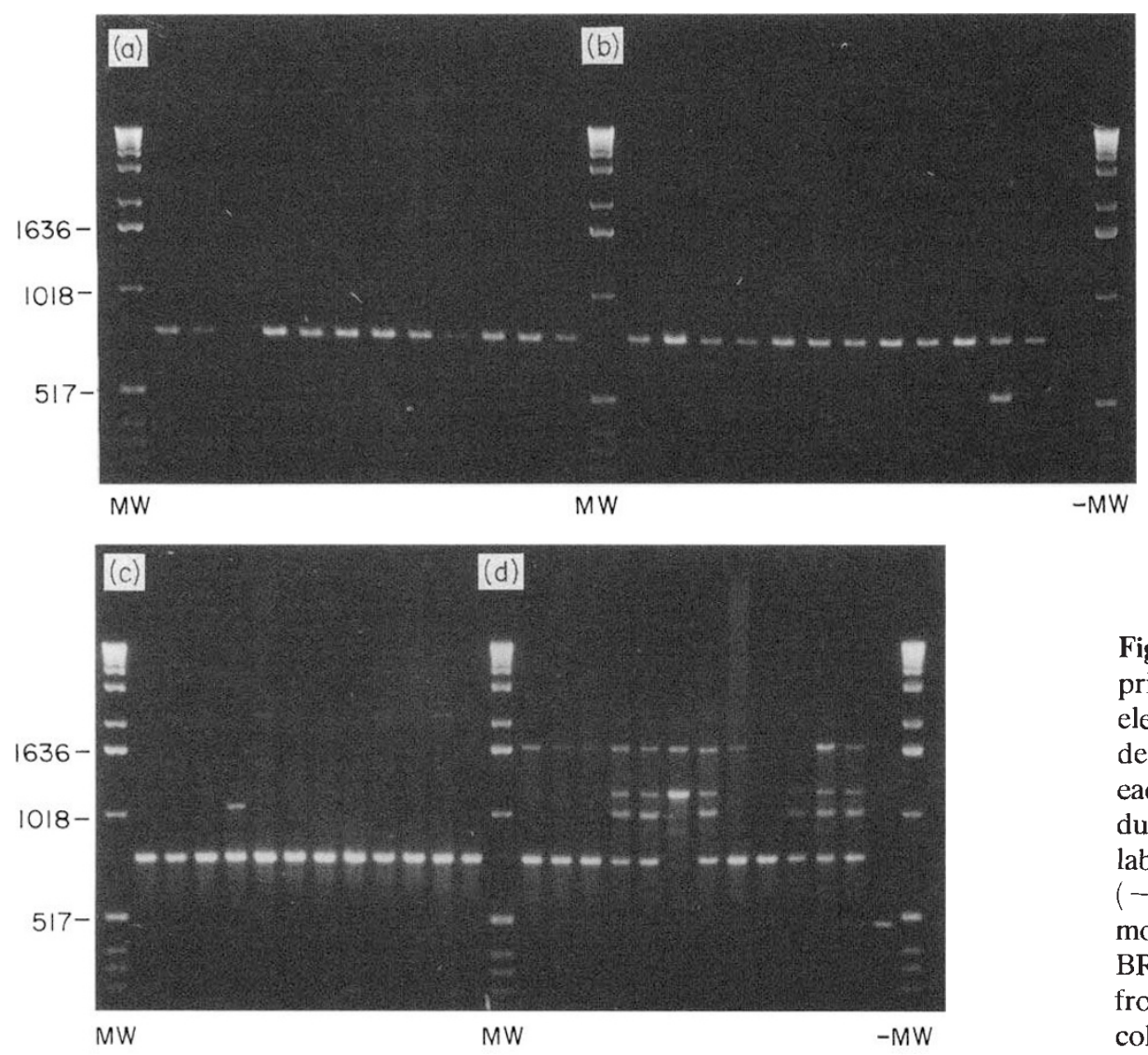

Fig. 3 Population profiles generated by primer GT09. The amplifications and electrophoresis were carried out as described in Materials and methods. In each lane are the amplification products of one individual from each of the labelled populations. The lanes marked $(-)$ are the negative controls. The molecular weight marker (MW) is the BRL $1 \mathrm{~kb}$ ladder. Population profiles from (a) Ruakura, (b) Uruguay, (c) Lincoln, and (d) Bariloche. 
Fig. 4 Population profiles generated by primer $267 / 2$. The amplification and electrophoresis were carried out as described in Materials and methods. In each lane are the amplification products of one individual from each of the labelled populations. The lanes marked $(-)$ are the negative controls. The molecular weight marker (MW) is the BRL $1 \mathrm{~kb}$ ladder. Population profiles from (a) Ruakura, (b) Uruguay, (c) Lincoln, and (d) Bariloche.
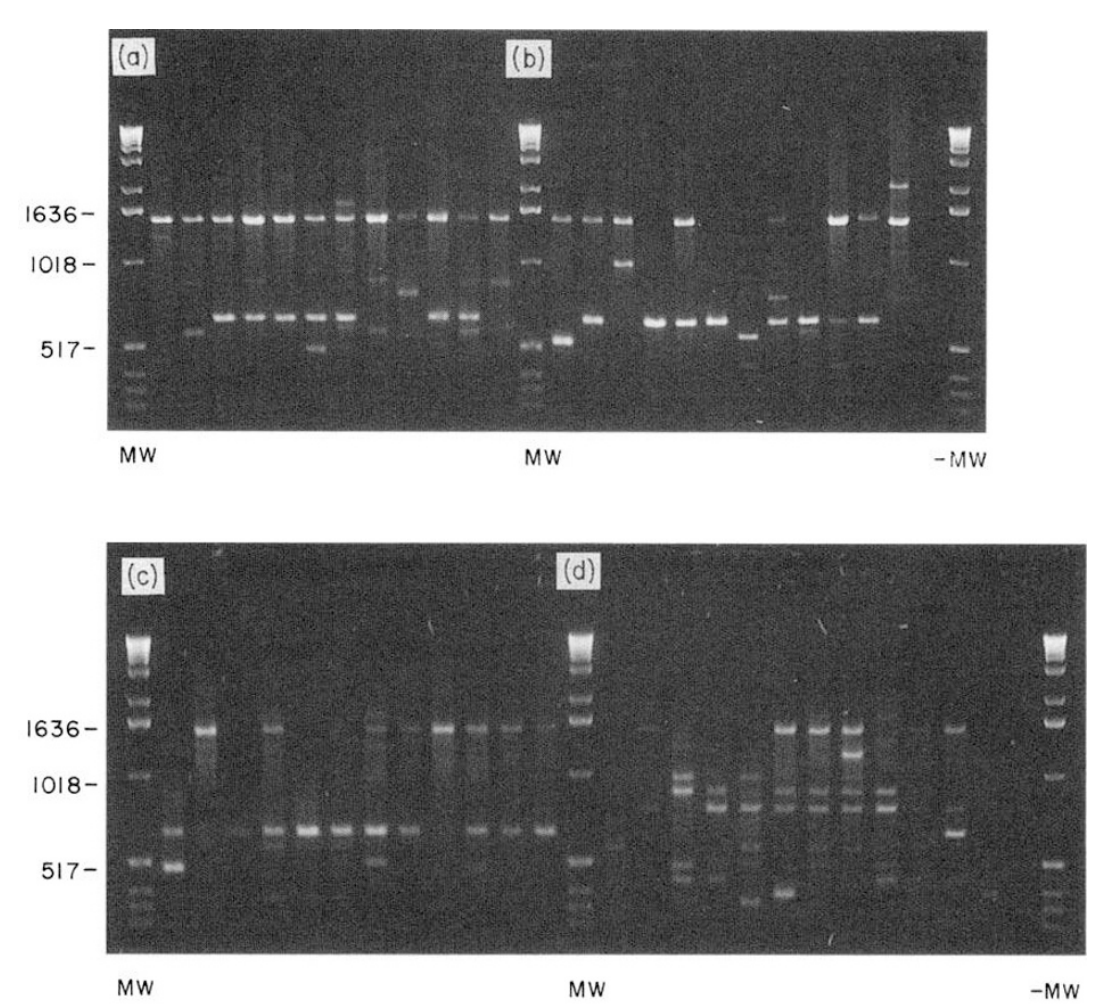

to each band based on approximate molecular weight. These band identification numbers were verified by running an aliquot of representative individuals from each gel that contained the band of interest side by side on a subsequent gel (verification gels not shown). Bands that ran at the same molecular weight were scored as the same band.

\section{Data analysis}

The presence/absence data matrix was analysed using the SAS procedure DISCRIM (Parker, 1987) (similar to Kambhampati et al., 1992). This procedure generated ordered canonical discriminant functions for the variables (bands). The means of three canonical discriminant functions for each of the sampled populations were plotted. The first two canonical discriminant functions were selected as the $x$ and $y$ axes. The third canonical discriminant function was selected as the $z$ axis, perpendicular to the plane of the page, and is represented in Fig. 5 by relative size of the letters representing the plotted values.

The data were also analysed by cluster analysis and principal coordinate analysis to verify that the results did not depend on the type of analysis used. Similarity matrices were calculated from the data on band presence or absence for each individual. Genetic distance or similarity were determined by Jacquard similarity, genetic distance (Gower, 1985), band sharing (Hedrick, 1985, and references therein), and
Nei and Li band sharing (Nei \& Li, 1979), again to provide cross-checks on interpretation. These individual similarity coefficients were reduced to population similarities by averaging individuals within populations. The similarity coefficients presented in Table 1 used the band-sharing measure of similarity (Hedrick, 1985, and references therein). The Nei and $\mathrm{Li}$ measure of band sharing was calculated from population frequencies to give the similarity between two populations. This measure was determined in two ways, using positive frequencies only, and using both positive and negative frequencies.

Dendrograms were constructed from the similarity matrices by hierarchical cluster analysis with an average link option using the GENSTAT program (Genstat 5 committee, 1987). The similarity matrices were also analysed in Genstat by principal coordinate analysis to generate a simpler display of the relationship between populations than the dendrogram.

\section{Results}

Primer GT09 generated 28 bands and primer $267 / 2$ generated 34 bands from the $174 \mathrm{~L}$. bonariensis studied. The number of bands generated for each individual varied from 1 to 12 . All distinct bands were included in the analysis.

Primer GT09 resulted in one prominent band of approximately $800 \mathrm{bp}$ in all the New Zealand populations, along with many other bands detectable at 


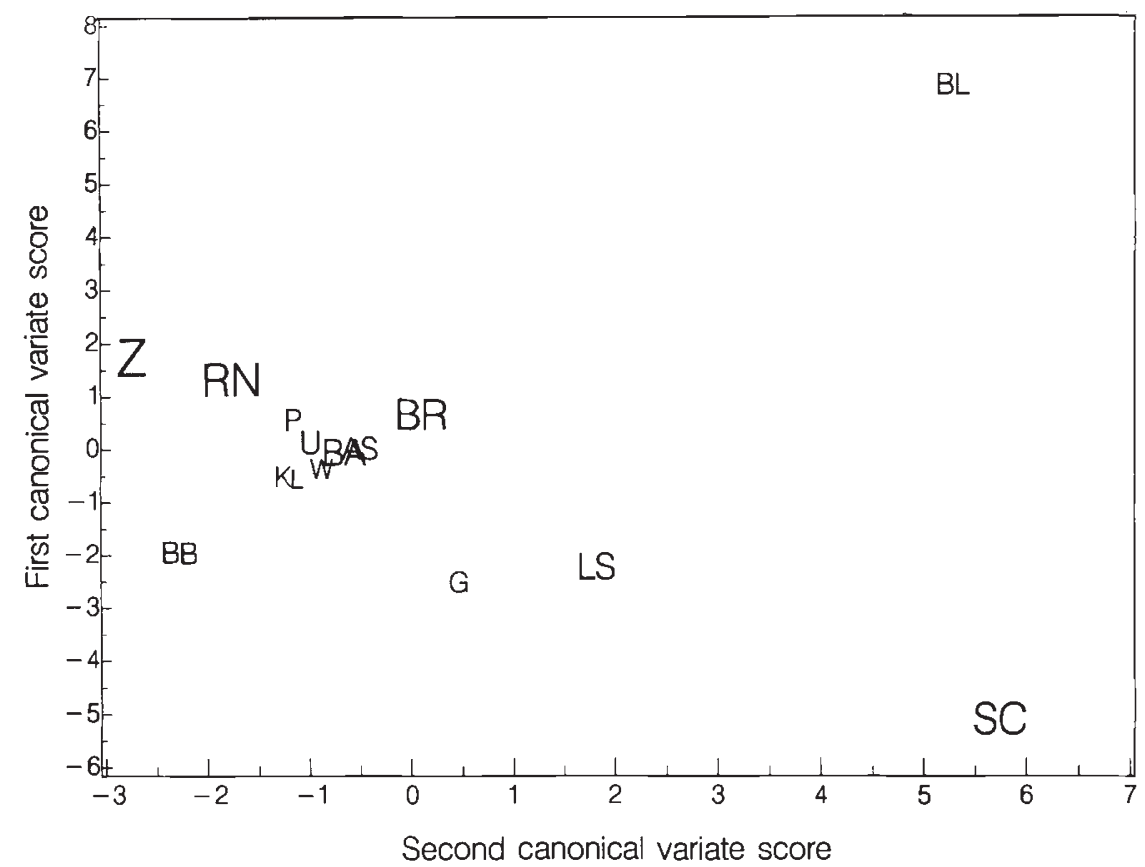

Fig. 5 A 3D distribution of sampled Listronotus bonariensis populations generated by the SAS procedure DISCRIM. The abbreviations used are: AS (Australia), BA (Buenos Aires), BB (Bahia Blanca), BL (Bariloche), BR (Brazil), G(Gore), K (Ruakura), L (Lincoln), LS (La Serena), P (Reporoa), RN (Rio Negro), SC (South Chile), U (Uruguay), W (Wellsford), Z (Mendoza). various molecular weights (e.g. Fig. 3, a and c). The Australian population also generated a similar banding pattern (not shown). Conversely, the South American populations generated quite diverse population profiles (e.g. Fig. 3, b and d). Using GT09, there was an apparent similarity between the New Zealand, the Australian and the Uruguayan profiles (Fig. 3, a and c, compared to $\mathrm{b}$ ). The Buenos Aires profile was also similar to these (not shown).

Primer 267/2 resulted in two prominent bands (1600 bp and $700 \mathrm{bp}$ ) in the New Zealand (Fig. 4, a and c) and Australian (not shown) populations. Other fragments were also generated, some individualspecific and others present in several individuals. Again, the South American population profiles were quite distinct from one another (e.g. Fig. 4, b and d). As with primer GT09, primer $267 / 2$ generated population profiles for the Uruguay and Buenos Aires populations, which closely resembled the New Zealand and Australian profiles (Fig. 4, a and c, compared to b).

The mean canonical variate scores for each population from the discriminant analysis (using the sAs procedure DISCRIM) of the presence/absence data matrix are plotted in Fig. 5. The mean scores for the New Zealand and Australian populations clustered in the vicinity of the means for the Uruguay and Buenos Aires populations (Fig. 5), supporting the initial impression based on visual examination of the gels. The population from Gore was slightly displaced from this cluster. In terms of the third canonical discriminant function (the $z$ axis)
Buenos Aires was slightly displaced from the New Zealand/Australia/Uruguay grouping. South Chile was split from the rest of the sampled populations by canonical discriminant function 2 and Bariloche was split from the rest of the populations by canonical discriminant functions 1 and 2 .

The population similarity matrix calculated by reducing the full shared fragment similarity matrix between individuals is given in Table 1. The New Zealand and Australian populations are most similar to each other and the Uruguayan population and to a slightly lesser degree to the Buenos Aires population. On the leading diagonal are values for within population similarity, which range from 0.388 to 0.647 . Four of the six introduced populations (Lincoln, Ruakura, Wellsford and Australia) exhibit a higher degree of within population similarity than the native populations. This reduction in intra-population variability is consistent with some sort of genetic 'bottleneck', such as a colonization event.

An example of the dendrograms generated using the band frequencies for each population is given in Fig. 6 . All five populations from New Zealand, the Australian population and Uruguay and Buenos Aires cluster as a distinct and separate group. This cluster was observed in all five dendrograms generated, with a minor amount of branch swapping noted. The clustering of the South American populations in some cases reflected the geographical distance separating the populations. For example, the Buenos Aires and Uruguay populations 


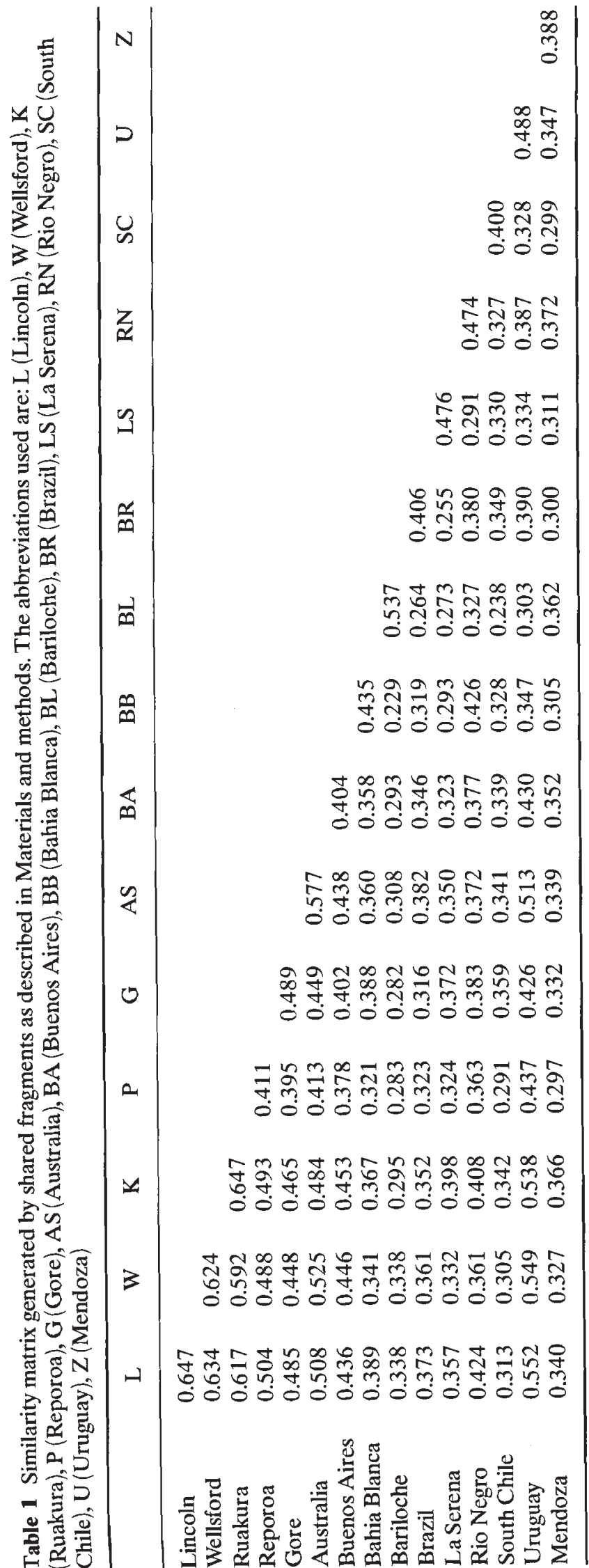

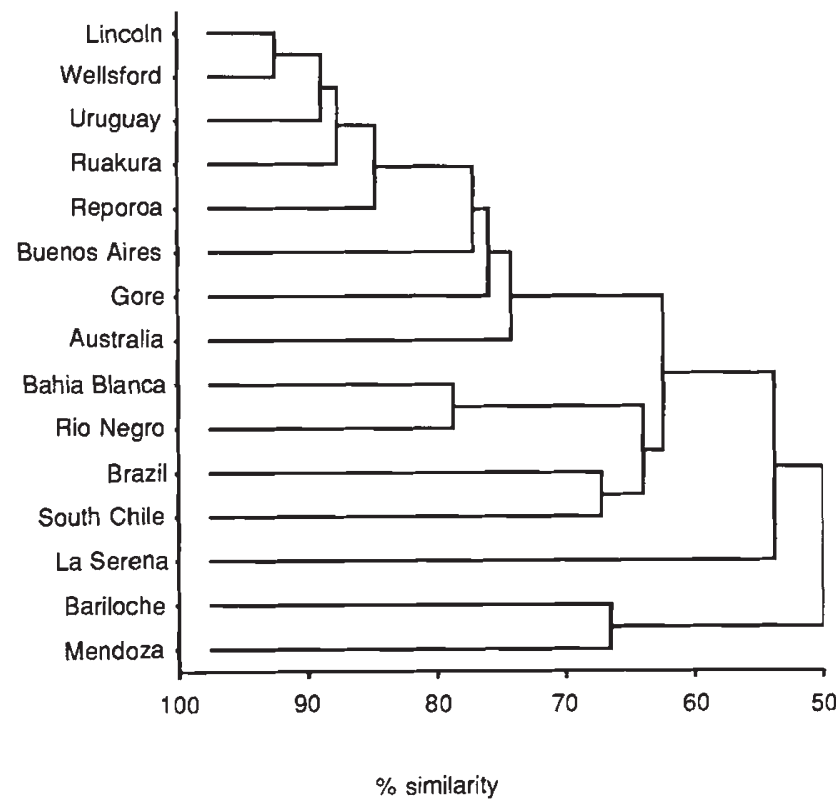

Fig. 6 Dendrogram of Listronotus bonariensis populations generated by average linkage cluster analysis using Nei and Li similarity based on shared fragments. For this dendrogram, only positive matches were counted.

cluster together and are only about $60 \mathrm{~km}$ apart. The populations from Bahia Blanca and Rio Negro also cluster together and are less than $100 \mathrm{~km}$ apart. There also were clusters of populations that were separated by fairly large distances. For example, the population from Brazil clustered with the population from South Chile.

\section{Discussion}

The bands generated using the RAPD technique are clearly genetic markers, albeit anonymous. The specific interpretation of these markers is open to discussion; however, for the purposes of this study they have proved useful.

The profiles generated by these primers indicated that the populations in South America are distinct from each other. This result suggests that (within the limits of the technique) most of these populations are to some extent genetically isolated, consistent with the geographical and climatic barriers that separate them.

Within New Zealand, most of the populations sampled generated very similar profiles. This suggests that within the limits of sampling, there is a high degree of genetic similarity between populations throughout the country.

The population from Australia generated a very similar profile to the New Zealand populations, indicating a strong genetic similarity between the weevils 
sampled in these countries. This suggests either that one of these countries was colonized by L. bonariensis from the other, or that both countries were colonized from a single source.

The New Zealand and Australian profiles closely resembled the profiles from the east coast of South America (Uruguay and Buenos Aires), indicating that there was significant genetic similarity between these populations. It should be noted that the Buenos Aires and Uruguay collection sites were only about $60 \mathrm{~km}$ across the Rio de la Plata from each other.

The populations from Brazil and South Chile clustered together in all of the dendrograms generated (e.g. Fig. 6). This clustering suggested that, despite the vast distance separating them, these populations were genetically similar (although not to the extent of the New Zealand group). To our knowledge, this is the first reported study on the population genetics of $L$. bonariensis, and the data suggest that there may have been some migration or colonizing events between these two populations. Further interpretation of the relationships between the South American populations may be possible using these data, but is beyond the focus of this study.

The dendrograms clearly showed that the South American populations clustering with the New Zealand/Australian populations are Buenos Aires and Uruguay. Although there was some branch swapping noted for the different dendrograms, this cluster was always present. The degree of similarity within this cluster is higher than between this cluster and the other South American populations. There is a lower degree of similarity between the rest of the South American populations, with the exception of Rio Negro and Bahia Blanca. Based on these results, the most likely geographical source of the introduced populations of L. bonariensis sampled in New Zealand and Australia is the Rio de la Plata region of South America.

The emphasis of this contribution has been to answer the question of where this pest originated and to make an approximation of when this occurred. Due to the geographical isolation of New Zealand and the limited flight capacity of $L$. bonariensis it is unlikely that $L$. bonariensis arrived in New Zealand prior to the onset of concerted trade and travel, about 150 years ago. It is also unlikely that any L. bonariensis have been introduced into New Zealand in the past 50 years, due to the strict importation and quarantine standards imposed. Thus, introduction has been limited to a finite time span. Exactly how this introduction occurred will never be known, but it is likely that $L$. bonariensis, being a grassland species, was present in the grasses or hay used as stockfeed on trading ships.
As an initial screen of the genetic makeup of the sampled L. bonariensis populations, RAPDs have provided new and useful information which will assist further research on this important agricultural pest. The results presented here demonstrate the use of the RAPD technique, which may have wide application in studies of other populations.

\section{Acknowledgements}

We are grateful to Ken Chalmers and Srinivas Kambhampati for their insights into data analysis. We also would like to thank Gail Timmerman and John Marshall for initially providing aliquots of primers, and Gary Barker, Paul Addison, Han Eerens and Steve Valentine for sample collection. This research was funded from a grant to the New Zealand Pastoral Agriculture Research Institute, Ltd. by the New Zealand Foundation for Research, Science and Technology.

\section{References}

BAKER, H. G. AND SteBbins, G. L. (eds) 1965. The Genetics of Colonizing Species. Academic Press, Inc., New York.

CHALMERS, K. J., WAUGH, R., SPRENT, J. 1., SIMONS, A. J. AND POWELL, w. 1992. Detection of genetic variation between and within populations of Gliricidia sepium and $G$. maculata using RAPD markers. Heredity, 69, 465-472.

CROWHURST, R. N., HAWTHORNE, B. T., RIKKERINK, E. H. A. AND TEMPLETON, M. D. 1991. Differentiation of Fusarium solanif. sp. cucurbitae races 1 and 2 by random amplification of polymorphic DNA. Curr. Genet., 20, 391-396.

GENSTAT 5 COMMITTEE, 1987. Genstat 5 Reference Manual. Oxford University Press, Oxford.

GOLDSON, S. L. AND EMBERSON, R. M. 1980. Relict diapause in an introduced weevil in New Zealand. Nature, 286, 489-490.

GOLDSON, S. L., MCNEILL, M. R., STUFKENS, M. W., PROFFITT, J. R., POTTINGER, R. P. AND FARRELL, J. A. 1990. Importation and quarantine of Microctonus hyperodae, a South American parasitoid of Argentine stem weevil. Proc. 43rd New Zeal. Weed and Pest Control Conf., 334-338.

GOWER, J. C. 1985. Measures of similarity, dissimilarity, and distance. In: Kotz, S., Johnston, N. L. and Read, C. B. (eds) Encyclopaedia of Statistical Sciences, vol. 5, pp. 397-405. Wiley, New York.

HADRYS, H., BALICK, M. AND SCHIERWATER, B. 1992. Applications of random amplified polymorphic DNA (RAPD) in molecular ecology. Mol. Ecol., 1, 55-63.

HARTL, D. L. 1980. Principles of Population Genetics. Sinauer Associates, Inc., Sunderland, MA.

HEDRICK, P. 1985. Genetics of Populations, pp. 72-73. Jones and Bartlett, Portola Valley, CA.

HEDR1CK, P. 1992. Shooting the RAPDs. Nature, 355, 679-680.

KAMBHAMPAT1, S., BLACK, W. C. IV, RAI, K. S. AND SPRENGER, D. 1990. Temporal variation in genetic structure of a colonising 
species: Aedes albopictus in the United States. Heredity, 64, 281-287.

KAMBHAMPATI, S., BLACK, W. C. IV AND RAI, K. s. 1991. Geographic origin of the US and Brazilian Aedes albopictus inferred from allozyme analysis. Heredity, 67, 85-94.

KAMBHAMPATI, S., BLACK, W. C. IV AND RAI, K. S. 1992. Random amplified polymorphic DNA of mosquito species and populations (Diptera: Culicidae): techniques, statistical analysis, and applications. J. Med. Entomol., 29, 939-945.

KELSEY, J. M. 1958. Damage in ryegrass by Hyperodes griseus Hust. New Zeal. J. Agric. Res., 1, 790-795.

LANDRY, B. S., DEXTRAZE, L. AND BOIVIN, G. 1993. Random amplified polymorphic DNA markers for DNA fingerprinting and genetic variability assessment of minute parasitic wasp species (Hymenoptera: Mymaridae and Trichogrammatidae) used in biological control programs of phytophagous insects. Genome, 36, 580-587.

MARSHALl, G. A. K. 1937. New Curculionidae (Col.) from New Zealand. Trans. Proc. New Zeal. Inst., 67, 316-340.

NEI, M. AND LI, W-H. 1979. Mathematical model for studying genetic variation in terms of restriction endonucleases. Proc. Nat. Acad. Sci. U.S.A., 76, 5269-5273.

PARAN, I., KESSELI, R. AND MICHELMORE, R. 1991. Identification of restriction fragment length polymorphism and random amplified polymorphic DNA markers linked to downy mildew resistance genes in lettuce, using near-isogenic lines. Genome, 34, 1021-1027.

PARKER, J. C. (ED.) 1987. SAS/STAT Guide for personal computers, Version 6. SAS Institute Inc., Cary, North Carolina.

PRESTIDGE, R. A., BARKER, G. M. AND POTTINGER, R. P. 1991. The economic costs of Argentine stem weevil in pastures in New Zealand. Proc. 44th New Zeal. Weed and Pest Control Conf., 165-170.

ROEHRDANZ, R. L. AND JOHNSON, D. A. 1988. Mitochondrial DNA variation among geographic populations of the screwworm fly, Cochliomyia hominivorax. J. Med. Entomol., 25, 136-141.

SMITH, M. L., BRUHN, J. N. AND ANDERSON, J. B. 1992. The fungus Armillaria bulbosa is among the largest and oldest living organisms. Nature, 356, 428-431.

TEMPLETON, A. R., SHAW, K., ROUTMAN, E. AND DAVIS, S. K. 1990. The genetic consequences of habitat fragmentation. Ann. Missouri Bot. Gard., 77, 13-27.

WELSH, J. AND MCCLELLAND, M. 1990. Fingerprinting genomes using PCR with arbitrary primers. Nucl. Acids Res., 18, 7213-7218.

WILLIAMS, J. G. K., KUBELIK, A. R., LIVAK, K. J., RAFALSKI, J. A. AND TINGEY, S. V. 1990. DNA polymorphisms amplified by arbitrary primers are useful as genetic markers. $\mathrm{Nucl}$. Acids Res., 18, 6531-6535. 